\title{
SÍNDROME DO ANTICORPO ANTIFOSFOLÍPIDE
}

\author{
ANTIPHOSPHOLIPID SYNDROME
}

Paulo Louzada Jr. ${ }^{1}$, Selvio Machado Simon ${ }^{2}$, Júlio C. Voltarelli ${ }^{3}$ \& Eduardo A. Donadi ${ }^{3}$

\begin{abstract}
${ }^{1}$ Médico Assistente, ${ }^{3}$ Docentes - Departamento de Clínica Médica do Hospital das Clínicas da Faculdade de Medicina de Ribeirão Preto da Universidade de São Paulo. ${ }^{2}$ Acadêmico da Faculdade de Medicina de Catanduva - SP.

CoRRESPONDÊNCIA: Departamento de Clínica Médica da Faculdade de Medicina de Ribeirão Preto - USP - Campus Universitário - 14048-900 Ribeirão Preto - SP
\end{abstract}

LOUZADA JR. P et al. Síndrome do anticorpo antifosfolípide. Medicina, Ribeirão Preto, 31: 305-315, abr./jun. 1998.

RESUMO: A Síndrome do Anticorpo Antifosfolípide (SAF) foi descrita recentemente e está associada a episódios de trombose venosa e arterial recorrentes, abortamento de repetição e trombocitopenia e, menos freqüentemente, à anemia hemolítica auto-imune e a manifestações cutâneas, cardíacas e neurológicas. Nesta revisão, discutem-se a fisiopatologia, o quadro clínico, a classificação e o tratamento da SAF e se analisam sessenta e nove (69) casos atendidos em nosso serviço.

UNITERMOS: Anticorpos Antifosfolipidios. Anticorpos Anticardiolipina. Inibidor de Coagulação do Lupus. Lupus Eritematoso Sistêmico. Trombose.

\section{INTRODUÇÃO}

A Síndrome do Anticorpo Antifosfolípide (SAF) caracteriza-se, principalmente, pelas manifestações clínicas e laboratoriais de trombose arterial e/ou venosa recorrentes, abortamentos de repetição e trombocitopenia, além de anemia hemolítica auto-imune (AHAI), alterações cardíacas, neurológicas e cutâneas. Hughes descreveu uma síndrome com essas características em $1983^{(1)}$, sendo que a associação com AHAI e manifestações cardíacas foi feita mais recentemente. $\mathrm{O}$ termo síndrome se justifica pela grande diversidade de quadros clínicos, particularmente a trombose, a perda fetal e a trombocitopenia, que podem ocorrer em associação com os antifosfolípides.

A SAF primária ou idiopática é aquela em que os anticorpos contra os fosfolipídios de membrana surgem sem nenhuma doença subjacente e a SAF secundária ocorre em associação com uma doença previamente existente, sendo comuns as associações com Lúpus Eritematoso Sistêmico (LES) e outras colagenoses, nas quais o anticoagulante ou inibidor lúpico (IL) também é comumente presente. Além disso, a SAF pode ser secundária a neoplasias (linfoma, leu- cemias), a doenças infecciosas (virais e bacterianas) ou ao uso de drogas (clorpromazina, hidralazina, fenitoína, procainamida, cocaína). Dentre as doenças autoimunes, o LES representa cerca de $50 \%$ dos casos, podendo também estar associadas à Doença Mista do Tecido Conectivo e às vasculites clássicas, como a Panarterite Nodosa, a Síndrome de Churg-Strauss, a Granulomatose de Wegener, a doença de Behçet e a Arterite de Takayasu. Em relação às doenças infecciosas, um grande espectro de patologias podem estar presentes, com etiologia viral ou bacteriana, devendo ser ressaltada a freqüência elevada (cerca de $70 \%$ ) de anticorpos de antifosfolípides em indivíduos portadores do vírus da imunodeficiência humana (HIV). Nesses indivíduos, os anticorpos antifosfolípides estão relacionados com o aparecimento da trombocitopenia, mas não com eventos trombóticos ${ }^{(2)}$, tornando, então, imperativa a pesquisa da infecção pelo HIV em todo paciente com as duas manifestações. Outras infecções, como rubéola, sarampo, caxumba, adenoviroses, hanseníase e micoplasmoses também podem originar anticorpos de anticardiolipina, porém de caráter transitório e não relacionados com trombose ${ }^{(1,3)}$. 
Os anticorpos antifosfolípides (aPL) estão associados com trombose, trombocitopenia, perdas fetais recorrentes e uma variedade de síndromes clínicas. Esses anticorpos podem ser identificados por testes imunoenzimáticos (ELISA) ou de coagulação, dependentes de fosfolípides. Quando detectados por ELISA, eles podem ser denominados de anticorpos de anticardiolipina (ACA), pois este fosfolípide de carga negativa é utilizado como antígeno. Quando detectados por testes de coagulação, dependentes de fosfolipídios, eles são denominados de anticoagulante ou inibidor lúpico $^{(1,3)}$.

\section{DEFINIÇÃO}

Com um quadro clínico e laboratorial tão exuberante e diversificado, o diagnóstico da SAF, para o clínico, pode se tornar difícil. Dessa forma, foram elaborados critérios diagnósticos clínicos e laboratoriais, suficientes para a realização do diagnóstico de SAF, que são apresentados na Tabela I.

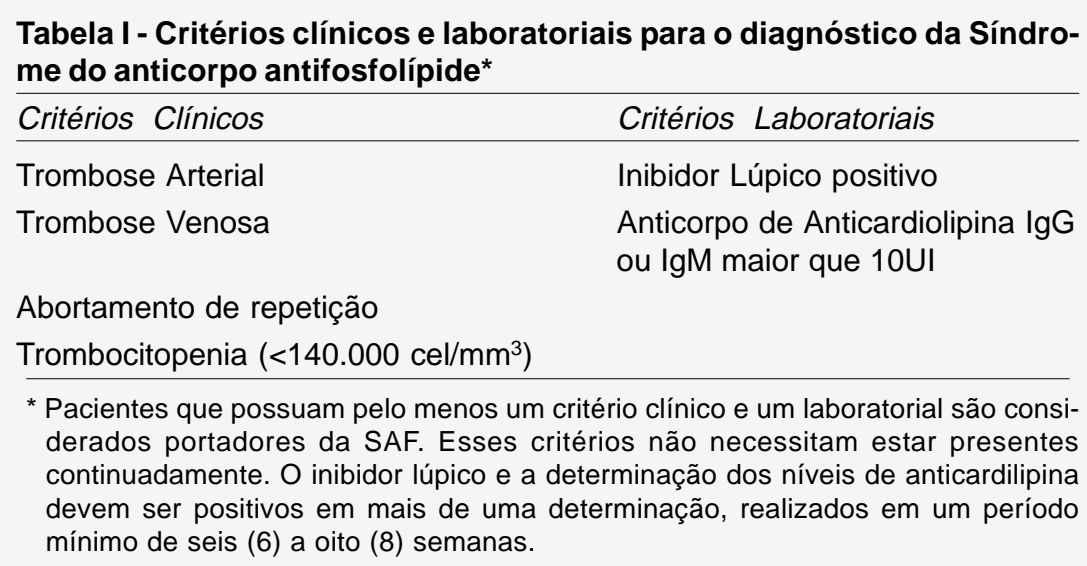

\section{O ANTICORPO ANTIFOSFOLÍPIDE}

Wasserman, em 1906, descobriu que indivíduos portadores de sífilis apresentavam anticorpo de anticardiolipina bovina. Mais tarde, foi verificado que esses anticorpos eram dirigidos contra estruturas fosfolipídicas, podendo aparecer em outras condições (testes falso-positivos) como:

a) agudo: associado a infecções virais;

b) crônico: associado à presença de colagenoses (sobretudo LES).

O anticorpo antifosfolípide, comum em pacientes luéticos, não traz complicações clínicas, mas, se asso- ciado ao LES, torna-se clinicamente relevante. As imunoglobulinas (Ig) envolvidas na SAF, associadas ao LES, são das subclasses IgG1, IgG2 e IgG3 e, na lúes, são encontradas as subclasses IgG1 e IgG3. Já a presença esporádica de IgG4, na Síndrome do Anticorpo Antifosfolípide, associada ao LES, levanta suspeita de cronicidade, devido ao fato de essa imunoglobulina ser responsável por uma imunidade prolongada ${ }^{(3)}$.

Em 1963, Bowie et al. observaram que alguns pacientes com LES e lúpus anticoagulante apresentavam trombose ao invés de sangramento, o que era esperado, pois os testes de coagulação estavam prolongados. Alguns desses pacientes também apresentavam reações falso-positivas para o teste do VDRL (Venereal Disease Reference Laboratory) $)^{(4)}$ para lúes. O componente reativo do antígeno VDRL, que é uma mistura complexa de lipídios, é um fosfolipídeo obtido a partir do músculo cardíaco, a cardiolipina. Em 1983, um teste de fase sólida foi desenvolvido para medir diretamente os níveis de anticorpos de anticardiolipina, a partir de amostras de plasma ou de soro ${ }^{(5)}$. Em 1983, Harris et al. ${ }^{(6)}$ foram capazes de definir a síndrome clínica associada aos anticorpos de anticardiolipina, caracterizada por: trombose, trombocitopenia e perda fetal recorrente. Embora o trabalho original tenha sido realizado identificando somente a cardiolipina, existe uma reatividade cruzada desses anticorpos com outros fosfolipídios, carregados negativamente (fosfatidil inositol difosfato, esfingomielinas, esfingocerebrosídeos, etc.), permitindo denominar esta patologia de Síndrome do Anticorpo Antifosfolípide (SAF) ${ }^{(5,6)}$.

Existem dois tipos de anticorpos antifosfolípides, denominados de Anticorpo de Anticardiolipina e o Inibidor Lúpico. O ACA pode ser uma IgG, se relacionar às tromboses venosas recorrentes, ou, então, uma IgM, se se relacionar a abortamentos de repetição e a tromboses arteriais recorrentes. $\mathrm{O}$ outro tipo de anticorpo, relacionado ao LES, que provoca anticoagulação in vitro, é denominado Inibidor Lúpico (IL), e está relacionado às tromboses arteriais recorrentes. $\mathrm{Na}$ SAF primária, encontra-se quase que exclusivamente o ACA e, na SAF secundária ao LES, o ACA pode estar presente conjuntamente com o $\mathrm{IL}^{(5)}$. Há 
semelhança entre o anticorpo antifosfolípide (AFL) e o anticorpo anti-DNA, pois a cabeça polar de fosfato do fosfolipídio é semelhante à estrutura fosfodiéster do DNA. Este fato poderia explicar a elevada freqüência de anticorpos anti-DNA e AFL no LES.

Os testes mais apropriados para se verificar a presença de anticoagulante lúpico são o Teste de Kaolin (KCT) e o do Tempo de Veneno de Cobra (TVC). O Tempo de Tromboplastina Parcialmente Ativada (TTPa) é menos sensível neste caso, porém é o teste mais usado. Neste teste, é realizado o TTPa do paciente e do controle e, a seguir, realiza-se a razão entre o TTPa do paciente e o do controle. Se essa razão for maior do que 1,3, o teste é considerado positivo; se menor do que 1,0 , é considerado negativo e, se permanecer entre 1,0 - 1,3, é duvidoso, devendo ser repetido três meses depois, caso o paciente não esteja utilizando terapia anticoagulante. Durante a realização do TTPa do paciente, também é feita uma diluição $(1: 1, \mathrm{v} / \mathrm{v})$ do plasma do paciente com o plasma de indivíduo normal (controle). Se houver deficiência de alguns fatores da cascata da coagulação, essa deficiência poderá ser corrigida com a adição do plasma controle. Porém, na SAF, tal correção não ocorre, mantendo o valor prolongado, pela presença dos anticorpos antifosfolípides, que funcionam como um anticoagulante (Tabela II). Esse fenômeno é aparentemente paradoxal, pois as alterações laboratoriais características de uma anticoagulação estão presentes em uma patologia que origina eventos trombóticos ${ }^{(7,8)}$.

O diagnóstico laboratorial das síndromes trombóticas antifosfolipídicas está resumido na Figura 1.
Tabela II - Prova do tempo da tromboplastina parcialmente ativada (TTPa) na síndrome do anticorpo antifosfolípide e na hemofilia sem inibidor da coagulação

\begin{tabular}{lll}
\hline Indivíduo & TTPa (plasma paciente) & TTPa (plasma paciente + controle) \\
\hline Normal & 25 a 35 segundos & 25 a 35 segundos \\
Hemofílico & 60 segundos & 30 segundos \\
SAF & 60 segundos & 60 segundos \\
\hline
\end{tabular}

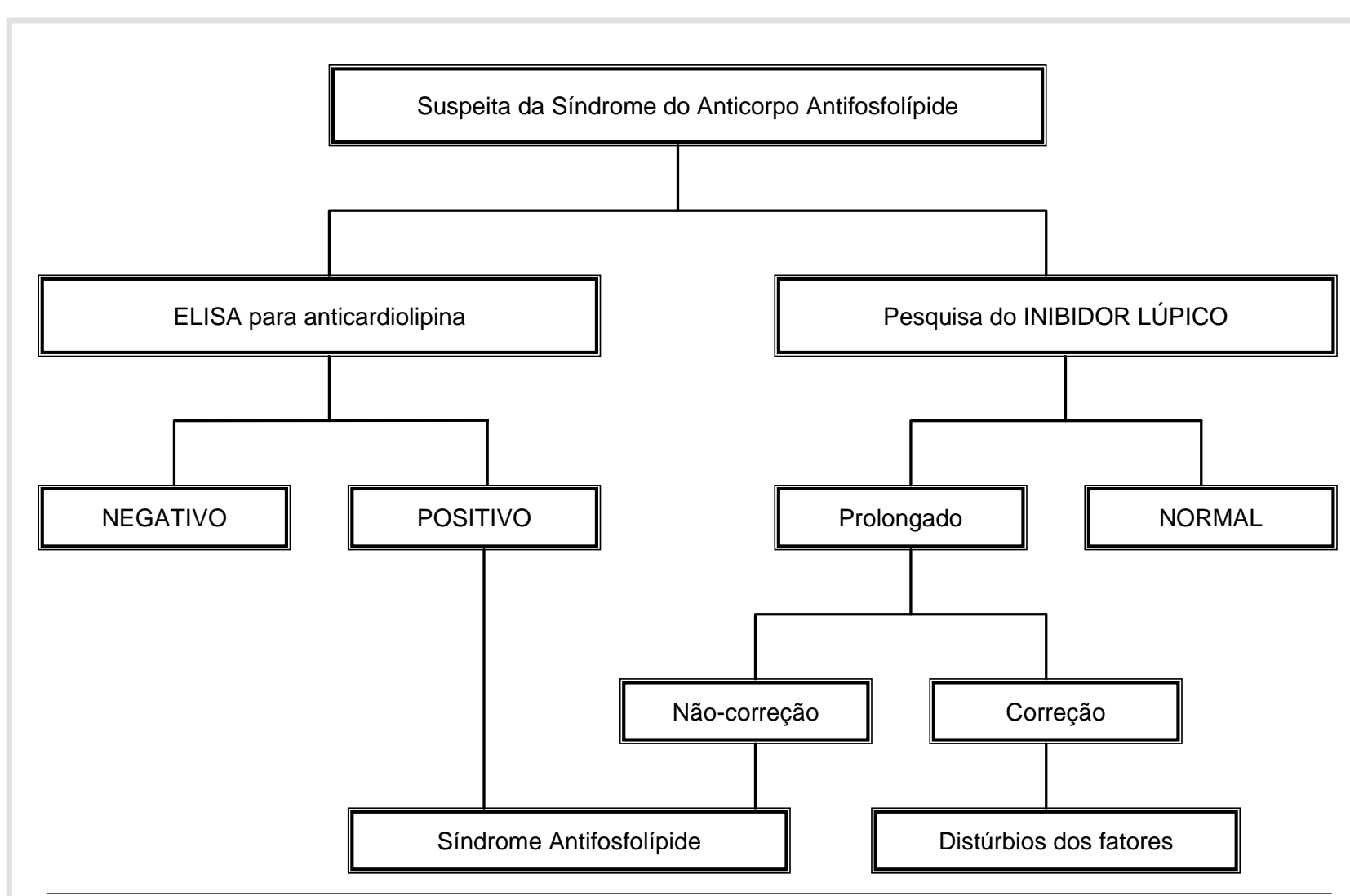

Figura 1 - Diagnóstico laboratorial das síndromes antifosfolipídicas. 


\section{MECANISMOS DE AÇÃO DOS ANTICORPOS ANTIFOSFOLÍPIDES NA SAF}

\subsection{Efeitos nos componentes vasculares da trombose}

Os mecanismos pelos quais anticorpos circulantes reagem contra fosfolípides intracelulares permanecem incertos. As células endoteliais são de crucial importância para a hemostasia, mantendo equilíbrio entre a coagulação e a anticoagulação, devido a uma série de fatores, tais como a capacidade para produzir moléculas semelhantes à heparina, trombomodulina, proteína $\mathrm{C}$, prostaciclina e outras. Os anticorpos anticélulas endoteliais têm sido descritos no LES, fazendo parte do espectro dos antifosfolípides, e são também observados em pacientes com esclerodermia, artrite reumatóide e outras colagenoses, possivelmente explicando discrasias da hemostasia nestas doenças ${ }^{(9)}$.

A maioria dos componentes do sistema de coagulação parece estar envolvida na patogenicidade dos anticorpos antifosfolípides (AFL), incluindo a cascata da coagulação, a ativação e a agregação plaquetárias. A interferência em qualquer um desses elementos pode ser um possível mecanismo de alteração hemostática $^{(9)}$.

O ACA, uma vez ligado aos fosfolipídios da membrana celular endotelial, compete com a cascata de ativação da coagulação, diminuindo a área de contato para a ligação dos fatores da coagulação, dependentes de vitamina $\mathrm{K}$, tendo, assim, um efeito anticoagulante paradoxal, evidenciado pelo aumento do TC, TTPa e outros testes simples da coagulação. A ação pró-coagulante vem dos anticorpos com efeito de IL, que se ligam aos fosfolipídios da membrana celular endotelial, inibindo, assim, a ativação da proteína $\mathrm{G}, \mathrm{o}$ que leva a não formação de segundo mensageiro (AMPc) por parte desta, afetando indiretamente a síntese de prostaciclina, o mais potente e natural antiagregante plaquetário conhecido. Desta forma, níveis reduzidos de prostaciclinas, secretadas pelas células endoteliais, permitirão a agregação plaquetária, havendo, assim, a formação de trombos até mesmo intraaórticos ou em locais de menor fluxo sangüíneo. Entretanto, para que tais anticorpos possam reagir com fosfolipídios das células endoteliais, é necessário que estas células estejam em estado de ativação ou rompidas, uma vez que os fosfolipídios estão localizados na face interna da membrana celular da célula endotelial ${ }^{(9)}$.

Os AFL também podem interferir com a atividade da proteína C. Esta é uma serina protease, dependente de vitamina $\mathrm{K}$, que possui ação anticoagu- lante por degradar os fatores Va e VIIIa, na presença de fosfolipídios, utilizando como cofator a proteína S. Essa atividade anticoagulante só pode ser exercida quando a proteína $\mathrm{C}$ é ativada pela trombina, na presença de trombomodulina, que é um componente da célula endotelial. Por sua vez, a trombomodulina pode ser alvo da ação dos AFL, já que é inibida por anticorpos anticoagulantes de frações de IgG. Por outro lado, fosfolipídios como a cardiolipina podem intensificar diretamente a ativação da proteína $\mathrm{C}$, através do complexo trombina-trombomodulina ${ }^{(9)}$.

$\mathrm{A}$ ativação reduzida da proteína $\mathrm{C}$ pode ainda afetar o sistema fibrinolítico, visto que esta proteína, em seu estado ativado, diminui a ação do inibidor do ativador do plasminogênio (IAP). Este é derivado de células endoteliais e funciona como importante modulador da ativação do plasminogênio. Assim, a proteína $\mathrm{C}$ pode, indiretamente, agir como promotora da fibrinólise. Nos casos de trombose no LES, os níveis séricos do ativador do plasminogênio estão muito reduzidos ${ }^{(9)}$.

Foi verificado, em grupos de pacientes com IL, que a atividade da pré-calicreína também está diminuída, fato que se soma à redução da atividade da proteína $\mathrm{C}$, explicando a inibição da fibrinólise. Os AFL podem inibir a atividade da antitrombina III, cuja função consiste em inibir a trombina e o fator Xa, ocasionando maior risco de trombose ${ }^{(9)}$.

A descoberta de uma reatividade cruzada entre anticorpos antifosfolípides, ácidos nucléicos e glicosaminoglicanos (GAGs) proporcionou explicações adicionais sobre a patogenia da SAF. Os glicosaminoglicanos, uma família de substâncias de estrutura molecular semelhante à heparina, fazem parte do principal componente endotelial não trombogênico. A inibição do potencial antitrombótico das GAGs, pela ligação com anticorpos antifosfolípides, poderia explicar, em parte, as tromboses associadas com a presença desses anticorpos. Dessa forma, a inibição da ativação da antitrombina III, dependente da heparina, poderia ser um dos mecanismos envolvidos no desenvolvimento das tromboses ${ }^{(9)}$.

Outro componente do endotélio vascular, as células endoteliais, também possuem uma participação importante no processo de trombose. Os anticorpos antifosfolípides aumentam a atividade procoagulante do endotélio, através do aumento da produção endotelial do Fator Ativador de Plaquetas (PAF) e da potencialização da ação da tromboplastina tecidual (Fator Tecidual) que aceleraria a via extrínseca da coagulação ${ }^{(10)}$ (Figura 1). 


\subsection{Efeitos dos AFL sobre as plaquetas}

Membranas obtidas a partir de superfícies ativadas são uma fonte muito importante de fosfolípidios carregados negativamente (p.ex. fosfatidilserina), proporcionando uma superfície catalítica para a interação dos fatores da coagulação. Nas plaquetas não ativadas, a fosfatidilserina está predominantemente localizada na superfície citoplasmática da membrana celular. Com a ativação plaquetária, esse fosfolípidio se torna expresso na parte externa da membrana celular. Os anticorpos antifosfolípides podem ativar as plaquetas e induzir a sua desgranulação por interagirem com proteínas situadas nas membranas plaquetárias. Estes anticorpos podem ser divididos em dois subgrupos ( $\mathrm{A}$ e $\mathrm{B}$ ), baseados na presença ou não da $\beta 2$-glicoproteína I. Na ausência da $\beta 2$-glicoproteína I, nenhum tipo de anticorpo anticardiolipina é capaz de inibir a atividade protrombinase das plaquetas (subgrupo A). Contudo, uma inibição dose, dependente da atividade protrombinase plaquetária, é observada após a adição da $\beta 2$-glicoproteína I (subgrupo B). Sendo assim, a atividade anticoagulante dos anticorpos antifosfolípides do subgrupo A é mediada pela $\beta 2-\mathrm{GPI}^{(9)}$.

A $\beta 2$-glicoproteína I ( $\beta 2$-GPI) age como cofator de ligação entre os aFL e os fosfolipídios. A presença dessa proteína plasmática, cuja concentração varia de 0 a $300 \mu \mathrm{g} / \mathrm{ml}$, ligando-se aos fosfolipídios aniônicos, inibe a ativação da fase de contato do sistema intrínseco da coagulação, além de inibir a agregação plaquetária mediada por ADP e a ativação da protrombinase de plaquetas ativadas, sendo, assim, um anticoagulante natural. O AFL pode se ligar ao complexo 32-GPI ou a um epítopo fosfolipídico por ela modificado, resultando em trombose ${ }^{(9)}$ (Figura 1).

Outro quadro da SAF, de etiologia desconhecida, é a trombocitopenia. Tem sido sugerido que a interação direta do antifosfolípide com a fosfatidilserina, na superfície das plaquetas ativadas, promove sua destruição e remoção pelo sistema retículoendotelial $^{(9)}$.

\subsection{Efeitos dos AFL sobre os componentes cir- culantes da trombose}

Os anticorpos antifosfolípides nos componentes circulantes da trombose, incluem a redução de fatores anticoagulantes, tais como a proteína $\mathrm{C} / \mathrm{S}$, a antitrombina III, as prostaciclinas ou a amplificação da atividade de fatores pro-coagulantes ${ }^{(9)}$.
Como mencionado anteriormente, a $\beta 2$-GPI é um cofator necessário para que os anticorpos antifosfolípides possam se ligar aos fosfolípides aniônicos. A $\beta 2-G P I$ é uma glicoproteína ligante de lipídios (também denominada de apolipoproteína $\mathrm{H}$ ou de apo $\mathrm{H}$ ), presente, normalmente, no plasma e funcionando como um anticoagulante natural. Ela inibe a fase de contato da coagulação (formação do complexo protrombinase), prevenindo a formação de trombina na presença de grânulos plaquetários ou de plaquetas ativadas, interferindo na agregação plaquetária, induzida pela adenosina difosfato (ADP). Dessa forma, a ligação de anticorpos antifosfolípides com a $\beta 2$-GPI pode induzir uma diátese protrombótica, relacionada com a presença de tais anticorpos $^{(9)}$ (Figura 1).

\subsection{Efeitos dos AFL sobre a gestação}

A perda fetal é uma manifestação clínica importante da presença dos anticorpos de anticardiolipina, pois eles inibem a secreção da gonadotrofina coriônica, afetando o desenvolvimento embrionário. Além disso, o anticorpo antifosfolípide interfere com um anticoagulante natural, a proteína placentária anticoagulante (PAP), que se liga com alta afinidade a fosfolipídios aniônicos. O AFL é um inibidor competitivo da PAP, sendo que altos títulos do anticorpo de anticardiolipina podem levar à trombose placentária e à perda fetal ${ }^{(9,10)}$ (Figura 2).

\section{ASPECTOS CLÍNICOS}

\subsection{Prevalência do Anticorpo Antifosfolípide}

A prevalência do Anticorpo antifosfolípide em pacientes com lúpus eritematoso sistêmico é de aproximadamente $40 \%$. O inibidor lúpico está presente em cerca de $30 \%$ dos casos. As manifestações clínicas da SAF, provavelmente, estão presentes em 30 a $40 \%$ dos pacientes que possuem tal anticorpo ou em cerca de 10 a $15 \%$ dos pacientes lúpicos. A prevalência da SAF primária varia de 7 a $30 \%$ nos pacientes que apresentaram episódios de trombose, sendo que, em indivíduos com idade inferior a cinquenta (50) anos, que apresentaram acidente vascular cerebral isquêmico não embólico, a prevalência do AFS é de 30\%. As perdas fetais recorrentes, em mulheres aparentemente saudáveis, são atribuídas à SAF, em cerca de 5 a $15 \%$ dos casos. A frequiência do Anticorpo antifosfolípide, em indivíduos saudáveis, é de $2 \%$, podendo aumentar com a idade ${ }^{(11,12,13)}$. 


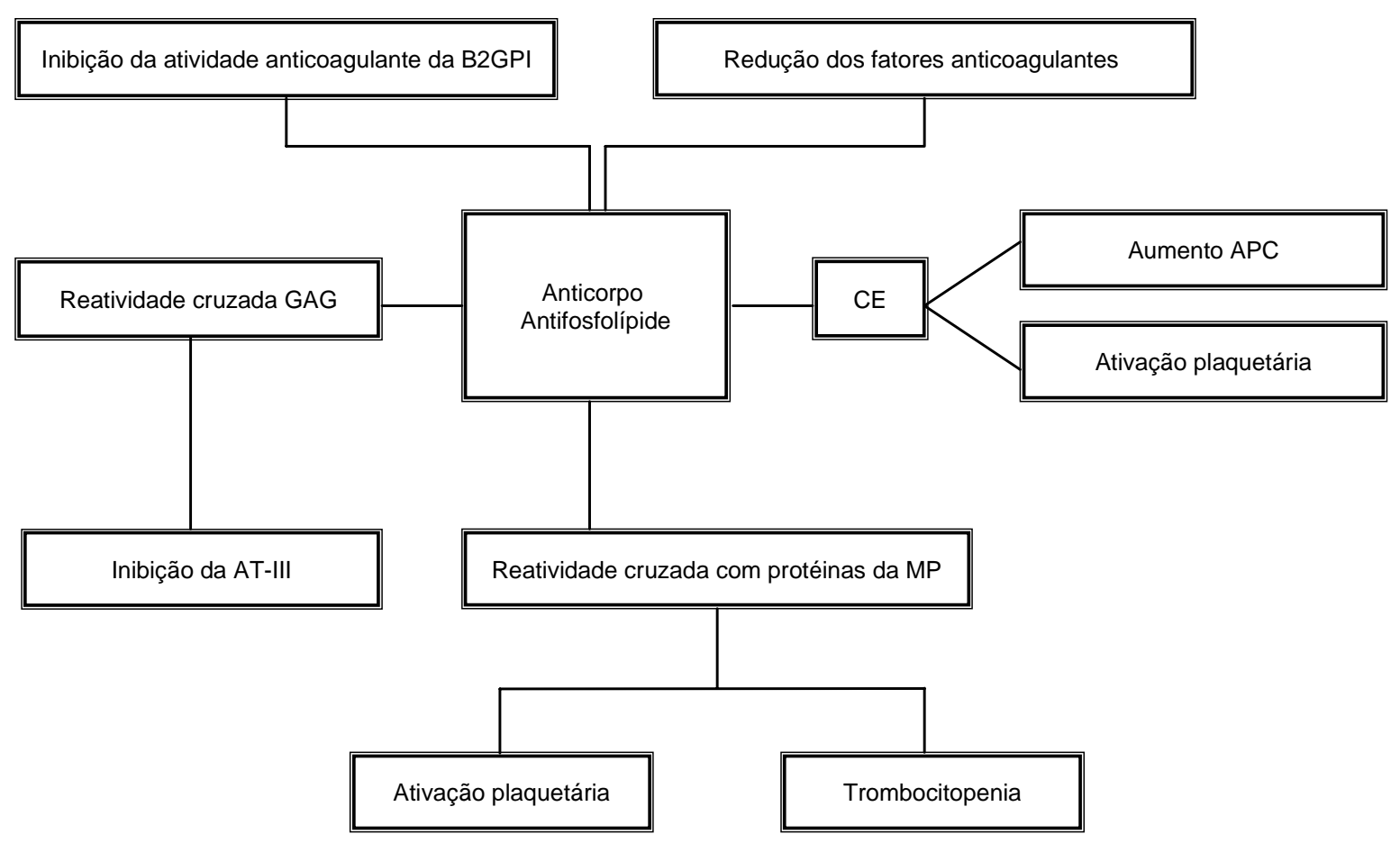

Figura 2 - Mecanismos de trombose e trombocitopenia. AT-III = anti-trombina III; APC= atividade pro-coagulante; $C E=$ célula endotelial; $B 2 G P I=B 2$-glicoproteína $I ; M P=$ membrana plaquetária.

\subsection{Tromboses arteriais e venosas}

Os eventos trombóticos, relacionados à $\mathrm{SAF}$, estão presentes em quase toda a árvore vascular. As veias superficiais e profundas dos membros inferiores são os locais mais freqüentes de trombose venosa. A trombose venosa profunda pode ser complicada por embolismo pulmonar em um terço dos casos. Outros locais acometidos por trombose podem ser as veias ilíacas, renais, hepáticas, retinianas, intracranianas e de membros superiores. $\mathrm{O}$ acidente vascular cerebral isquêmico é a forma mais comum de trombose arterial, observada nos pacientes portadores de anticorpos antifosfolípide. Além desses, outros locais podem ser acometidos como as artérias coronarianas, as carótidas, as retinianas, as subclávias ou as axilares (síndrome do arco aórtico), as braquiais, as mesentéricas, as periféricas de extremidades e as aortas, proximal e distal. A trombose pode ser ocasionada pela presença de uma doença subjacente em pacientes com AFS, como, por exemplo, quadros de perda gestacional (trombose e infarto placentário), de disfunção renal (trombose de vasos intra-renais), de úlceras cutâneas (trombose de vasos da derme), de certas formas de doenças do sistema nervoso central (demência por multiinfartos) e de hipertensão pulmonar (embolia pulmonar recorrente) $)^{(11,12,13,14)}$.

As síndromes trombóticas, associadas aos anticorpos de anticardiolipina, são classificadas, segundo Bick, 1994 ${ }^{(14)}$, da seguinte forma:

- Síndrome tipo I: trombose venosa profunda com ou sem trombose pulmonar;

- Síndrome tipo II: trombose das artérias coronarianas; trombose das artérias periféricas; trombose aórtica; trombose das artérias carótidas;

- Síndrome tipo III: trombose da artéria retiniana; trombose da veia retiniana; trombose cerebrovascular; ataques isquêmicos cerebrais transitórios;

- Síndrome tipo IV: combinações dos tipos I, II e III, que são raras.

Com a experiência crescente na utilização do ensaio para anticardiolipina, na prática clínica, tornase cada vez mais claro que as síndromes antifosfolipídicas são muito mais freqüentes do que se suspeitava. A avaliação diagnóstica do paciente para determinar a causa de ampla variedade de distúrbios trombóticos precisa incluir, hoje em dia, o ensaio para anticorpos de anticardiolipina. Embora seja correto suspeitar da existência desses anticorpos em quase todos os proble- 
mas clínicos complicados pela trombose, certas apresentações são indicações mais claras do que outras ${ }^{(14)}$.

Nos pacientes com a síndrome tipo I, é conveniente ter elevado índice de suspeita, principalmente nos pacientes com trombose venosa, profunda, não acompanhada de um fator de risco potencial, como a administração exógena de estrogênio, cirurgia, imobilização prolongada, neoplasia maligna ou outro estado hipercoagulável. Como se observa na prática clínica, os pacientes podem ser encaminhados para a avaliação apenas depois de um segundo episódio de trombose. O primeiro evento trombótico pode ter aparentemente resultado de um problema predisponente identificável e, somente depois, se comprovar que estava associado a anticorpos de anticardiolipina. Embora a gravidade ou localização (ileofemoral, veia poplítea da panturrilha ou outros locais) da trombose, ou a existência de embolização pulmonar, não se correlacione com a presença dos anticorpos de anticardiolipina, os fenômenos tromboembólicos recorrentes ou tromboses em vários locais devem sugerir imediatamente à existência desses anticorpos ${ }^{(14)}$.

Os pacientes com síndrome do tipo II, freqüentemente, se apresentam com uma condição catastrófica. A história de infarto agudo do miocárdio, em idade jovem, infartos recorrentes do miocárdio, obstrução precoce de enxerto após cirurgia de revascularização coronariana e recorrência precoce da obstrução após angioplastia transluminar são típicos. Alguns pacientes têm trombose aórtica, subclávia, mesentérica, femoral ou de outros vasos calibrosos, com obstrução completa e sintomas agudos de isquemia e perda iminente da extremidade. O diagnóstico imediato e o tratamento adequado podem salvar a vida do paciente ${ }^{(14)}$.

Os pacientes da síndrome do tipo III podem ser encaminhados por vários problemas. Perda aguda ou distorção da visão leva à confirmação oftalmológica da trombose da artéria retiniana. Sintomas neurológicos focais podem sugerir a existência de trombose cerebrovascular, resultando em sintomas de síncope ou ataque isquêmico transitório. Alternativamente, a demência por múltiplos infartos pode instalar-se de forma mais gradativa, sem síncopes agudas nitidamente definidas. O diagnóstico precoce é fundamental nos pacientes com a síndrome do tipo III, porque o atraso na aplicação do tratamento pode acarretar lesão cerebral irreversível ${ }^{(14)}$.

Esta classificação de trombose é importante sob o ponto de vista terapêutico, pois a medicação anticoagulante a ser empregada é baseada nessa classificação, mesmo parecendo não haver correlação com o tipo ou título do anticorpo de anticardiolipina e a classificação da síndrome ${ }^{(14)}$.

\subsection{Abortamentos de repetição}

Os pacientes com LES têm alta prevalência de abortos espontâneos, e as mulheres com anticorpos antifosfolípides têm $50 \%$ de chance de apresentarem perda fetal. Em adição à perda fetal, os anticorpos antifosfolípides também podem estar associados com o aumento na incidência de complicações obstétricas e pós-natais, incluindo a pré-eclâmpsia, sofrimento fetal, retardo do crescimento intra-uterino, parto prematuro e eventos trombóticos maternos no período pós-parto. A maioria dos casos de perda fetal relacionada com o Anticorpo antifosfolípide são precedidos de retardo no crescimento intra-uterino e oligoidraminios. A placenta apresenta-se diminuta e, histologicamente caracteriza-se por uma vasculopatia com infartos difusos ${ }^{(11,12,15)}$.

Os anticorpos de anticardiolipina também estão associados a uma síndrome pós-parto, típica, com febre, dor torácica pleurítica, dispnéia, derrame pleural, infiltrados pulmonares e arritimias ventriculares. Geralmente, a síndrome ocorre de dois (2) a dez (10) dias após o parto ${ }^{(11,12,15)}$.

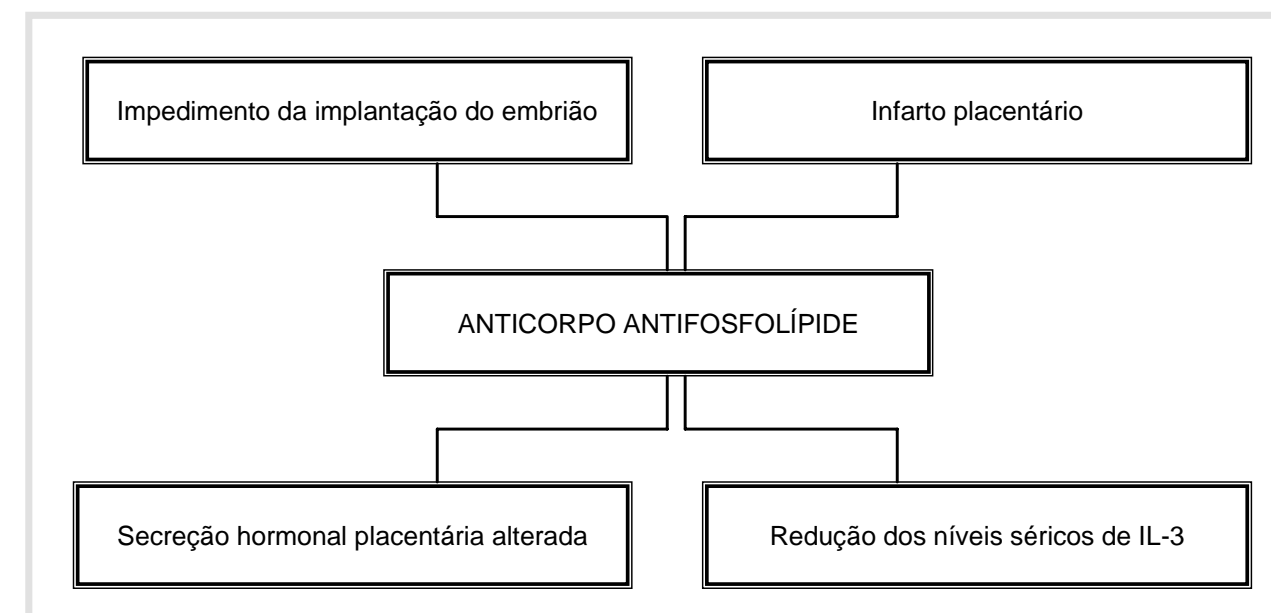

Figura 3 - Mecanismos de perda fetal na SAF. 


\subsection{Manifestações hematológicas}

A trombocitopenia, em pacientes com lúpus eritematoso sistêmico, pode estar associada com a presença de anticorpo antifosfolípide, estando presente em $70 \%$ dos pacientes. Em pacientes com SAF, a trombocitopenia é geralmente moderada $(>50.000 \mathrm{cel} /$ $\mathrm{mm}^{3}$ ) e não está associada com hemorragias. A trombocitopenia observada em indivíduos portadores do vírus da imunodeficiência humana está relacionada com a presença do anticorpo antifosfolípide em cerca de 70 a $80 \%$ dos casos. A anemia hemolítica autoimune ocorre em cerca de $30 \%$ dos pacientes com SAF, sendo que na Síndrome de Evans (anemia hemolítica auto-imune e trombocitopenia), a presença de antifosfolípide ocorre em cerca de $90 \%$ dos pacientes. A maioria das manifestações da SAF estão correlacionadas com o isótipo $\operatorname{IgG}$, ao passo que a anemia hemolítica está associada com anticardiolipina do isotipo $\operatorname{IgM}^{(11,12,13)}$.

\subsection{Manifestações dermatológicas}

As manifestações dermatológicas são comuns da SAF. O livedo reticularis (erupção purpúrica, mosqueada, mais proeminente nas extremidades) é provavelmente secundário à trombose de pequenos vasos. Está associado a trombose venosa e arterial recorrentes, a doenças valvulares e a tromboses cerebrovasculares com hipertensão essencial concomitante (Síndrome de Sneddon) ${ }^{(13,16)}$. Outras manifestações cutâneas presentes em pacientes com LES e antifosfolípide incluem tromboflebites superficiais, úlceras cutâneas de membros inferiores, piodermites, gangrena digital, cianose distal dos dedos, necrose cutânea generalizada e doença de Degos. O reconhecimento precoce desses sinais cutâneos, relativamente benignos, é importante, pois, eles podem ser os preditivos de eventos trombóticos graves, em muitos pacientes $(13,14,16)$.

\subsection{Manifestações cardíacas}

Anormalidades cardíacas são comuns em pacientes com LES e anticorpos antifosfolípide, sendo caracterizadas pela presença de vegetações, regurgitação e estenose valvulares. A insuficiência valvular, a trombose das artérias coronárias e a endocardite de Libman-Sacks (vegetações verrucosas, não infecciosas) também podem ocorrer ${ }^{(13,14)}$.

\subsection{Manifestações neurológicas}

As síndromes neurológicas, associadas aos anticorpos de anticardiolipina, mais freqüentes, in- cluem ataques isquêmicos cerebrais, transitórios e acidentes vasculares, cerebrais, isquêmicos, não embólicos. Algumas das manifestações neurológicas não são necessariamente secundárias à trombose, como a coréia. Assim, alguns pacientes com coréia apresentaram infartos, porém, outros casos resolvem espontaneamente ou sem terapia anticoagulante. Outras manifestações neurológicas, associadas com a SAF, são doenças obstrutivas dos vasos da retina, migrânea, síndrome de Sneddon, convulsões, mielite transversa e neurite óptica ${ }^{(14,16,17)}$.

\subsection{Manifestações renais}

Aparecem oclusões vasculares, manifestando-se através de hipertensão arterial, perda insidiosa da função renal (mesmo na ausência da proteinúria) e dor abdominal por infarto renal ou trombose da veia renal $^{(11,13)}$.

\subsection{Síndrome do antifosfolípide catastrófica}

Uma síndrome aguda disseminada, com oclusões vasculares múltiplas, associada com a presença de anticorpos antifosfolípide, tem ocorrido num pequeno número de pacientes. Os quadros mais freqüentemente observados são disfunção renal, doença cerebrovascular, infarto do miocárdio e hipertensão. A maioria dos pacientes relatam uma história de LES leve ou inativo, com ou sem história anterior de SAF. Os títulos de anticardiolipina IgG estão elevados e o inibidor lúpico positivo. Um evento precipitante, tal como uma infecção viral, utilização de medicamentos ou o período pós-parto, pode estar presente em alguns casos. Esta síndrome é fatal em $40 \%$ dos $\operatorname{casos}^{(18)}$.

\section{TRATAMENTO}

Os riscos associados com níveis moderados ou elevados de anticorpo antifosfolípide são relevantes, sendo que o risco relativo da ocorrência de trombose venosa profunda, embolismo pulmonar ou de acidente vascular, isquêmico, em indivíduos com idade inferior a cinquenta (50) anos é de sete (7) a oito (8) vezes maior do que na população normal. Por outro lado, há poucos ensaios terapêuticos, controlados, para a SAF, e o tratamento permanece empírico, apesar de que alguns princípios tenham surgido a partir de experiência clinica de alguns centros de referência ${ }^{(14,19)}$.

\subsection{Trombose}

Pacientes com história de trombose e níveis significantes de AFS possuem risco elevado para 
recorrência de trombose. A prevenção dos eventos trombóticos é feita através de terapia anticoagulante por longos períodos. Considerando os riscos de tal tratamento, a decisão de anticoagulação deve ser individualizada e inúmeros fatores devem ser considerados, incluindo o nível do anticorpo, o tipo e a precocidade do evento trombótico, e a idade do paciente. Há uma diferenciação do tipo de anticoagulante a ser utilizado, de acordo com o local da trombose. Se ela ocorreu no sistema venoso dos membros inferiores, com ou sem embolismo pulmonar (síndrome do tipo I), ou no sistema arterial periférico (síndrome tipo II), opta-se pelo uso de heparina subcutânea, 5.000 U, de doze (12) em doze (12) horas, ou de heparinas de baixo peso molecular (fraxeparina, enoxeparina), $40 \mathrm{mg} / \mathrm{dia}, \mathrm{SC}$. Freqüentemente, esses pacientes não respondem ao tratamento com antagonistas da vitamina K. Porém, se ela ocorreu em artérias retinianas ou artérias cerebrovasculares (síndrome tipo III), os anticoagulantes preferencialmente utilizados são os antagonistas da vitamina K (fenprocumona, warfarin), mantendo o valor de INR entre 3,5 a 4,5, associado ao uso de ácido acetilsalicílico, em baixas doses. O uso de imunossupressores ou corticosteróides somente é feito para o tratamento da doença de base (LES ou outra colagenose), sendo que, em nosso serviço, não foi encontrada diminuição sensível do título de anticorpo antifosfolípide com seu uso (vide abaixo). $O$ uso de anticoagulação não deve ser descontinuado sob o risco de repetição da trombose ou perda fetal, a não ser em raros casos, quando o nível do anticorpo antifosfolípide tornou-se negativo por mais de três $\operatorname{meses}^{(14,19)}$.

\subsection{Abordagem terapêutica de gestantes por- tadoras do anticorpo de anticardiolipina}

Os anticorpos dos antifosfolípides estão associados à incidência elevada de abortamento fetal, perda fetal no segundo $\left(2^{\circ}\right)$ e terceiro $\left(3^{\circ}\right)$ trimestres, vasculite placentária e trombocitopenia materna. As mulheres com ACA positivo têm probabilidade de abortamento em cerca de $50 \%$ e o tratamento anticoagulante bem sucedido pode aumentar para $80 \%$ as chances de um parto a termo normal. Cerca de $2 \%$ das gestações aparentemente normais possuem ACA ou IL positivos e $0,2 \%$ os possuem em altos títulos ${ }^{(14,15,19)}$.

\subsubsection{Primíparas lúpicas}

Em mulheres com LES, cerca de 1/3 apresentam ACA positivo. Primíparas lúpicas possuem alto risco de perda gestacional, que está correlacionada com os níveis do anticorpo de antifosfolipídico. Todas as primíparas com títulos moderados ou elevados de ACA devem ser monitoradas para alterações nas plaquetas (contagem mensal) e para crescimento fetal anormal. Nessas pacientes, utiliza-se o ácidoacetilsalicílico, como antiagregante plaquetário, na dose de $100 \mathrm{mg} /$ dia e observação mensal rigorosa. Se a contagem das plaquetas for menor do que $70.000 / \mathrm{mm} 3$, iniciar prednisona $1,0 \mathrm{mg} / \mathrm{kg} / \mathrm{dia}$ e Imunoglobulina Intravenosa, na dose de $2,0 \mathrm{~g} / \mathrm{kg} / \mathrm{mês}^{(14,15,19)}$.

\subsubsection{Multíparas com perdas fetais recorren- tes e ACA positivo}

Cerca de $10 \%$ das mulheres que possuem história de perda de pelo menos, duas gestações apresentam ACA positivo, em títulos elevados. Elas necessitam de tratamento profilático, que é dividido em três fases, de acordo com o tempo gestacional:

Fase I: de 0 a $12^{\text {a }}$ semana: AAS $100 \mathrm{mg} / \mathrm{dia}$ diminui o risco de pré-eclâmpsia e o retardo de crescimento intra-uterino.

Fase II: da $13^{\mathrm{a}}$ a $32^{\mathrm{a}}$ semana: heparina SC, 2.500 - 5.000U, de 12 em 12 horas.

Fase III: da $33^{\mathrm{a}}$ semana até o parto: AAS 100 $\mathrm{mg} / \mathrm{dia}$.

Alguns serviços mantêm a dose da heparina acima referida até o final da gestação (risco maior de osteopenia materna). A prednisona é utilizada somente quando há sintomas relacionados com a atividade do LES. É de se destacar que o uso de varfarina, na gestação, demonstrou ser teratogênico, sendo, assim, descontinuado seu uso ${ }^{(14,15,19)}$.

\section{3. Trombocitopenia}

Trombocitopenia moderada (contagem de plaquetas $>50.000 / \mathrm{mm}^{3}$ ) usualmente não requer tratamento. Níveis mais reduzidos podem necessitar de tratamento com corticóides e, caso não ocorra resposta, é empregado o uso de Imunoglobulina Humana Intravenosa, na dose de $2,0 \mathrm{~g} / \mathrm{kg} / \mathrm{mês}$, durante um período mínimo de seis (6) meses ${ }^{(14,19)}$. Nos pacientes HIV positivos, deve-se evitar o uso de corticóides e a trombocitopenia pode responder à terapia antiretroviral (vide Secção 7).

\subsection{SAF catástrofica}

Devido ao número limitado de casos, a combinação de plasmaférese e anticoagulação parece ser o 
tratamento de escolha para essa síndrome. A terapia imunossupressora, incluindo pulsos de corticosteróides, é geralmente inefetiva ${ }^{(18)}$.

\subsection{Pacientes assintomáticos}

Utiliza-se o ácido acetilsalicílico, em baixas doses, como terapia profilática, porém, não sendo consenso, por falta de evidências controladas que apóiem tal recomendação ${ }^{(11 / 14)}$.

\section{EXPERIÊNCIA DO HCFMRP}

Estudamos o quadro clínico e laboratorial de sessenta e nove (69) pacientes com SAF, atendidos no Ambulatório de Doenças Reumáticas da Divisão de Imunologia Clínica da Faculdade de Medicina de Ribeirão Preto-USP entre 1986 e 1998. Entre eles, quarenta e seis (46) eram do sexo feminino e vinte e três (23) do sexo masculino, sendo $87 \%$ caucasóides, $8 \%$ mulatos, $3 \%$ negros e $1,5 \%$ asiáticos, com idade variando de três (3) a sessenta e cinco (65) anos (mediana de trinta e cinco (35) anos). O diagnóstico da síndrome foi confirmado pela detecção de anticorpo de anticardiolipina por ELISA, em títulos superiores a 5,0 UI; além disto, $41 \%$ dos pacientes apresentavam anticoagulante lúpico e 16\%, VDRL falso-positivo para lues. Em relação à etiologia, 36\% apresentavam Lúpus Eritematoso Sistêmico (L.E.S.), 39\% eram HIV positivos e somente $25 \%$ manifestavam a SAF na forma primária. Quanto ao quadro clínico, 50\% apresentavam trombocitopenia, $10 \%$ perdas fetais recorrentes e 55\% tiveram trombose. Entre estes, a trombose arterial foi observada em 26\% (artéria cerebral média: $50 \%$, cerebral anterior: $20 \%$, carótida: $20 \%$, pediosa e tibial posterior: $10 \%$ ) e a trombose venosa em $29 \%$ dos pacientes (panturrilha: 50\%, pulmonar: 20\%, femural: $10 \%$, cava inferior e renal: $10 \%$ ). Nos pacientes HIV positivos, a presença do ACA correlacionou-se com estágio avançado da doença e com a ocorrência de trombocitopenia, mas não se observou nenhum episódio tromboembólico.

Os pacientes com SAF secundária ao LES receberam tratamento imunossupressor, dirigido à doença de base, geralmente contendo ciclofosfamida EV, enquanto os pacientes com SAF primária foram tratados apenas com anticoagulantes. Nos dois grupos, os títulos de anticorpos de anticardiolipina mantiveram-se inalterados, ocorrendo dois (2) óbitos por trombose cerebral e quatro (4) episódios de recorrência de trombose. Nos pacientes HIV positivos, a trombocitopenia respondeu ao uso de anti-retrovirais, dispensando a imunossupressão.

LOUZADA JR. P et al. Antiphospholipid Syndrome. Medicina, Ribeirão Preto, 31: 305-315, apr./june 1998.

ABSTRACT: The antiphosfolipide syndrome (APS) was recently described and is associated with arterial and venous thrombosis, repeated abortions, thrombocypoenia and, less frequently, with autoimmune hemolitic anemia and cutaneous, cardiac or neurologic manifestations. This review discusses pathophysiology, clinical presentation and treatment of APS and includes an analysis of 69 cases seen in our clinic.

UNITERMS: Antibodies, Antiphospholipid. Antibodies, Anticardiolipin. Lupus Coagulation. Inhibitor. Lupus Erythematosus Systemic. Thrombosis.

\section{REFERÊNCIAS BIBLIOGRÁFICAS}

1 - HUGHES GRV. Thrombosis, abortion, cerebral disease, and the lupus anticoagulant. BMJ 287: 1088-1089, 1983.

2 - LOUZADA-JR P. et al. Síndrome do Antifosfolipídeo em indivíduos trombocitopênicos e infectados pelo vírus da imunodeficiência humana. Rev Bras Reumatol 36: 279,1996

3 - HARRIS NE; GHARAVI AE \& BOEY ML. Clinical and serological features of the "antiphospholipid syndrome" (APS). Br J Rheumatol 26:19, 1987.
4 - BOWIE EJW; THOMPSON JH \& PASCUZZI CA. Thrombosis in SLE despite circulating anticoagulant. $\mathbf{J}$ Lab Clin Med 62: 416-430, 1963

5 - ASHERSON RA; KHAMASHTA MA \& GIL A. The "primary" antiphospholipid syndrome: major clinical serological features. Medicine 68: 366-374, 1989.

6 - HARRIS EN et al. Anticardiolipin antibodies by radioimmunoassay and association with thrombosis in systemic lupus erythematosus. Lancet II: 1211-1214, 1983. 
7 - LOUZADA-JR P et al. Retrospective analysis of 301 patients whose sera were tested for antiphospholipid antibodies. Rev Bras Reumatol 35: 22-23,1995.

8 - HARRIS EN et al. Thrombosis, recurrent fetal loss, thrombocytopenia: predictive value of $\operatorname{lgG}$ anticardiolipin antibodies. Arch Intern Med 146: 2153-2156, 1986.

9 - ARON AL; GHARAVI AE \& SHOENFELD Y. Mechanisms of action of antiphospholipid antibodies in the antiphospholipid syndrome. Int Arch Allergy Immunol 106: 8-12, 1995.

10 - MERONI PL; DEL PAPA N; BORGHI MO. Antiphospholipid and antiendotelial antibodies. Int Arch Allergy Immunol 111: 320-325, 1996.

11 - HARRIS EN; KHAMASHTA MA \& HUGHES GRV. Antiphospholipid antibody syndrome In: MCCARTY DJ \& KOOPMAN WJ eds, Arthritis and allied conditions, 13th ed, Lea \& Febiger, Philadelphia, p. 1201-1213,1997.

12 - GHARAVI AE \& WILSON WA. Antiphospholipid antibodies. In: WALLACE DJ \& HAHN BH eds. Dubois lupus erythematosus. 5th ed, Williams \& Wilkens, Baltimore, p. 471-492, 1997.

13 - McCARTY GA. The lupus anticoagulant and antiphospholipid antibodies In: WALLACE DJ \& HAHN BH, eds. Dubois' lupus erythematosus. 5th ed, Williams \& Wilkins, Baltimore, p.493-504, 1997
14 - BICK RL \& BAKER WF. O antifosfolipídio e as síndromes trombóticas. Clin Med Am Norte 3: 685-702, 1994.

15 - WELCH S \& BRANCH DW. Antiphospholipid syndrome in pregnancy: obstetric concerns and treatment Rheum Dis Clin North Am 23: 71-84,1997.

16 - ASHERSON RA \& HARRIS EN. Anticardiolipin antibodies: Clinical associations. Postgrad Med J 62: 1081-1087, 1986

17 - GINBURG KI; LIANG MH \&NEWCOMER L. Anticardiolipin antibodies and the risk for ischemic stroke and venous thrombosis. Ann Intern Med117: 997-1002,1997.

18 - ASHERSON RA. The catastrophic antiphospholipid syndrome. J Rheumatol 19: 508-512, 1992.

19 - PETRI M. Pathogenesis and treatment of the antiphospholipid antibody syndrome. Adv Rheumatol 81: 151-177, 1997

Recebido para publicação em 13/05/98

Aprovado para publicação em 10/06/98 